\title{
Actions in Support of Newborn Screening for Critical Congenital Heart Disease — United States, 2011-2018
}

Jill Glidewell, MSN, MPH${ }^{1}$; Scott D. Grosse, $\mathrm{PhD}^{1}$; Tiffany Riehle-Colarusso, $\mathrm{MD}^{1}$; Nelangi Pinto, $\mathrm{MD}^{2}$; Jeff Hudson, MA²; Rachel Daskalov, MHA2; Amy Gaviglio, $\mathrm{MS}^{3}$; Erin Darby, $\mathrm{MPH}^{4}$; Sikha Singh, MHS; Marci Sontag, $\mathrm{PhD}^{5}$

In 2011, the U.S. Department of Health and Human Services added critical congenital heart disease (CCHD), which occurs in two of every 1,000 births, to the list of conditions recommended to states for universal newborn screening (1). Without early detection, infants with CCHD are at risk for substantial morbidity and death in the first weeks and months of life (2). Based on 2007-2013 data, deaths from CCHD and other cardiac causes in infants aged $<6$ months significantly declined in infants born in eight states after they had fully implemented mandated newborn CCHD screening policies by June 2013 (3). CDC collaborated with the American Academy of Pediatrics (AAP) and the Association of Public Health Laboratories' Newborn Screening Technical Assistance and Evaluation Program (NewSTEPs) to update a 2015 report (4) on states' actions toward adopting and implementing policies supporting CCHD newborn screening. In 2018, all 50 states and the District of Columbia (DC) had implemented CCHD screening policies, and, with one exception, all states mandated that screening be done (California mandates that screening be offered). However, not all states had data systems in place for tracking all screening results and outcomes. Ongoing evaluation activities, which rely on screening data, could help identify program improvement opportunities and monitor the impact of early identification of CCHD.

Congenital heart defects occur in approximately eight of every 1,000 live births; one fourth of infants born with congenital heart defects have CCHD $(1,2)$. CCHD typically requires surgical or catheter intervention before age 1 year (2). Newborn screening can identify newborns with CCHD before signs or symptoms are evident and before hospital discharge after birth. CCHD screening supplements clinical detection of CCHD to facilitate timely identification, treatment, and management of affected infants. Infants are screened for CCHD using pulse oximetry, a noninvasive method to estimate the oxygen saturation in an infant's arterial blood. Hypoxemia (abnormally low oxygen saturation) detected by pulse oximetry screening can result from $\mathrm{CCHD}$ or other causes. Additional testing (e.g., chest radiograph or echocardiography) is needed after an abnormal screen to determine the cause of the hypoxemia $(2,5,6)$.

CDC, AAP, and NewSTEPs assessed actions by states (i.e., legislation, regulations, or both) toward adoption and implementation of policies supporting CCHD newborn screening. In the context of this report, a statute is a law enacted by a state legislature and signed into law, a regulation is considered to be a rule promulgated by a state agency with the force of law, and legislation is a bill reviewed and acted upon by a state legislature. Policies include statutes, regulations, and other measures, such as appropriations. The effective date of a statute can differ from the date it is implemented by health care providers. For example, Maryland enacted a screening mandate in May 2011 that legally took effect in July 2011 (4). However, the effect of the statute was to direct the state health department to begin the process of preparing regulations that, once issued, would require hospitals and other delivery care providers to screen for CCHD. The date on which the Maryland screening mandate was actually implemented at the provider level was September 1, 2012 (3). In this report, the implementation date is the date when providers were expected or required to begin universal screening of newborns for CCHD.

AAP and NewSTEPs used several methods to gather and compile enactment, effective, and implementation dates of screening policies, as well as information on screening data collection and data sharing. AAP monitored state legislation using legal and regulatory tracking software and researched regulatory and hospital guidelines on state websites. AAP obtained primary information through direct contact and partnership with AAP state chapters. State-specific information on collection of screening data elements was provided by state CCHD screening programs directly to the NewSTEPs Data Repository (7). NewSTEPs surveyed state CCHD newborn screening coordinators to assess data sharing and collaboration between birth defects surveillance programs, which track cases of CCHD, and newborn screening programs. Newborn screening programs in all 51 jurisdictions ( 50 states and DC) participated in the survey.

From 2013 to 2018, the number of jurisdictions that had implemented CCHD screening policies increased from 22 to 51 (Table 1). States used various approaches to adopt newborn screening for CCHD. Thirty-nine (76\%) jurisdictions adopted statutes that either mandated screening or the offer of screening or called for the issuance of regulations to mandate that screening be offered; the other 12 jurisdictions implemented mandates exclusively through regulations. The content of policies varies among states. For example, in 2015, Colorado mandated that infants born in a birthing center located below 7,000 feet elevation be screened for CCHD (infants born at 


\begin{tabular}{|c|c|c|c|c|c|c|c|}
\hline State & Citation & Statute* & $\begin{array}{l}\text { Regulation/ } \\
\text { Guidance }^{\dagger}\end{array}$ & Actions & Date enacted & Date effective & $\begin{array}{l}\text { Date universal } \\
\text { screening policy } \\
\text { implemented } \\
\text { im }\end{array}$ \\
\hline Alabama & Ala. Admin. Code 420-10-1 & - & $x^{9}$ & Mandates screening & May 2013 & Jun 2013 & Jun 21, 2013 \\
\hline \multirow[t]{2}{*}{ Alaska } & Alaska Stat § 18.15.205 & $x^{\pi}$ & - & Mandates screening & Sep 2013 & $\begin{array}{l}\text { Jan } 2014 \text { (Jan } 2016 \\
\text { for providers } \\
\text { who attend } \\
<20 \text { births/yr) }\end{array}$ & Mar 19, 2014 \\
\hline & $\begin{array}{l}\text { Alaska Admin. Code tit. 7, § } 27.630 \\
\text { Alaska Admin. Code tit. 7, § } 27.635\end{array}$ & - & $x$ & $\begin{array}{l}\text { Specifies type of provider who is } \\
\text { required to perform screen; } \\
\text { reporting requirements }\end{array}$ & Feb 2014 & Mar 2014 & \\
\hline \multirow[t]{2}{*}{ Arizona } & Ariz. Rev. Stat. § 36-694 & $x^{\pi}$ & - & Mandates screening & Apr 2014 & Jul 2014 & Jul 1, 2015 \\
\hline & Ariz. Admin. Code § R9-13-202 & - & $x$ & $\begin{array}{l}\text { Screening and reporting } \\
\text { requirement }\end{array}$ & May 2015 & Jul 2015 & \\
\hline Arkansas & Ark. Code Ann. § 20-9-13 & $x^{\pi}$ & - & Mandates screening & Apr 2013 & Aug 2013 & Jul 1, 2015 \\
\hline California & Cal. Hsc. Code $\S 124121$ & $x$ & - & Mandates screening be offered & Sep 2012 & Jan 2013 & Jul 1, 2013 \\
\hline \multirow[t]{2}{*}{ Colorado } & Colo. Rev. Stat. § 25-4-1004.3 & $X^{\mathbb{1}}$ & - & $\begin{array}{l}\text { Mandates screening in birthing } \\
\text { facilities below } 7,000 \mathrm{ft} \text {. altitude }\end{array}$ & May 2015 & Aug 2015 & Jan 1, 2016 \\
\hline & Colo. Rev. Stat. § 12-37-105 & $x$ & - & $\begin{array}{l}\text { Mandates direct entry midwives } \\
\text { perform screen** }\end{array}$ & Jun 2016 & Aug 2016 & \\
\hline Connecticut & Conn. Gen. Stat. § 19a-55 & $x^{\pi}$ & - & Mandates screening & May 2012 & Jan 2013 & $\operatorname{Jan} 1,2013$ \\
\hline Delaware & 16 Del. Admin. Code $\S 4107.4$ & - & $x^{\pi}$ & Mandates screening & May 2013 & May 2013 & May 1, 2013 \\
\hline $\begin{array}{l}\text { District of } \\
\text { Columbia }\end{array}$ & D.C. Code § 7-857.02 & $x^{\pi}$ & - & Mandates screening & Jun 2015 & Sep 2015 & Sep 7, 2015 \\
\hline Florida & Fla. Admin. Code r. 64C-7.002 & - & $x^{\Uparrow}$ & Mandates screening & Oct 2014 & Oct 2014 & Mar 26, 2015 \\
\hline Georgia & Ga. Comp. R. and Regs. 511-5-5-.03 & - & $x^{\pi}$ & Mandates screening & May 2014 & Jun 2014 & Jul 1, 2015 \\
\hline Hawaii & Haw. Rev. Stat. § 321-296 & $x^{\pi}$ & - & Mandates screening & Jul 2015 & Jul 2015 & Jan 2014 \\
\hline Idaho & Idaho. Admin. Code. r. 16.02.12.301 & - & $x^{\pi}$ & Mandates screening & Jul 2018 & Jul 2018 & Jul 1, 2018 \\
\hline Illinois & 410 III. Comp. Stat. § 240/1.10 & $x^{\pi}$ & - & Mandates screening & Aug 2013 & Aug 2013 & Aug 20, 2013 \\
\hline Indiana & Ind. Code $\S 16-41-17-2$ & $x^{n}$ & - & Mandates screening & May 2011 & Jan 2012 & Jan 1, 2012 \\
\hline \multirow{2}{*}{ lowa } & lowa Code $\S 136 \mathrm{~A} .5 \mathrm{~A}$ & $X^{\Uparrow}$ & - & Mandates screening & Jun 2013 & Jul 2013 & $\operatorname{Jan} 8,2015$ \\
\hline & lowa Admin. Code r. 641.4 .3 & - & $x$ & $\begin{array}{l}\text { Screening and reporting } \\
\text { requirements }\end{array}$ & Dec 2014 & Jan 2015 & \\
\hline Kansas & Kan. Admin. Regs. § 28-4-502 & - & $X^{\pi}$ & Mandates screening & Feb 2018 & Feb 2018 & Feb 2018 \\
\hline \multirow[t]{2}{*}{ Kentucky } & Ky. Rev. Stat. Ann. § 214.155 & $x^{\pi}$ & - & Mandates screening & Mar 2013 & Jan 2014 & Jan 1, 2014 \\
\hline & 902 Ky. Admin. Regs. 4:030 & - & $x$ & $\begin{array}{l}\text { Screening and reporting } \\
\text { requirements }\end{array}$ & Dec 2013 & Dec 2013 & \\
\hline Louisiana & La. Stat. Ann. § 40:1083.3 & $X^{\mathbb{1}}$ & - & Mandates screening & Jun 2013 & Aug 2013 & Aug 1, 2013 \\
\hline \multirow[t]{2}{*}{ Maine } & Me. Stat. tit. 22, § 1532 & $x^{9}$ & - & Mandates screening & Jul 2013 & Jul 2013 & Oct 9, 2013 \\
\hline & 10-144 Me. Code. R. 709 & - & $x$ & $\begin{array}{l}\text { Screening and reporting } \\
\text { requirements }\end{array}$ & Sep 2015 & Sep 2015 & \\
\hline \multirow[t]{3}{*}{ Maryland } & Md. Code, Health. Law § 13-111 & $x^{\pi}$ & $x$ & $\begin{array}{l}\text { Mandates screening and creates } \\
\text { advisory committee to develop } \\
\text { implementation } \\
\text { recommendations }\end{array}$ & May 2011 & Jul 2011 & Sep 1, 2012 \\
\hline & Md. Code Regs. 10. 52.15.01-.08 & - & $x$ & $\begin{array}{l}\text { Screening and reporting } \\
\text { requirements }\end{array}$ & Oct 2012 & $\begin{array}{l}\text { Oct } 2012 \\
\text { (emergency } \\
\text { adoption) } \\
\text { Apr } 2013 \\
\text { (permanent } \\
\text { adoption) }\end{array}$ & \\
\hline & Md. Code, Bus. and Occ. Law $\S 8-6 C-2$ & $x^{9}$ & - & $\begin{array}{l}\text { Mandates direct entry midwives** } \\
\text { perform screen }\end{array}$ & May 2015 & Jun 2015 & \\
\hline \multirow[t]{3}{*}{ Massachusetts } & Mass. Gen. Laws ch. 111, § $110 \mathrm{C}$ & $x^{\pi}$ & - & Mandates screening & Mar 2014 & Jun 2014 & Jun 2014 \\
\hline & 105 Code Mass. Regs. 142.303 & - & $x$ & $\begin{array}{l}\text { Requires freestanding birth } \\
\text { centers to develop screening } \\
\text { protocols }\end{array}$ & Oct 2014 & Jan 2015 & \\
\hline & 105 Code Mass. Regs. 130.616 & - & $x$ & $\begin{array}{l}\text { Requires hospitals to develop } \\
\text { screening protocols }\end{array}$ & Oct 2014 & Jan 2015 & \\
\hline Michigan & $\begin{array}{l}\text { CCHD mandate letter to hospital } \\
\text { administrators (authority under } \\
\text { Mich. Comp. Laws } \S 333.5431 \text { ) }\end{array}$ & - & $x^{\pi}$ & Mandates screening & Oct 2013 & Apr 2014 & Apr 1, 2014 \\
\hline Minnesota & Minn. Stat. § 144.1251 & $x^{\Uparrow}$ & - & Mandates screening & May 2013 & Aug 2013 & Aug 1, 2013 \\
\hline Mississippi & Miss. Code R. § 15.4.1.1 & - & $x^{\pi}$ & Mandates screening & Oct 2014 & Nov 2014 & Jul 1, 2015 \\
\hline Missouri & Mo. Rev. Stat. § 191.334 & $x^{\pi}$ & - & Mandates screening & Jul 2013 & Aug 2013 & $\operatorname{Jan} 1,2014$ \\
\hline Montana & Mont. Admin. R. 37.57.305 & - & $x^{\pi}$ & Mandates screening & Jun 2014 & Jul 2014 & Jul 1, 2014 \\
\hline \multirow[t]{2}{*}{ Nebraska } & Neb. Rev. Stat. § 71-556 & $x^{n}$ & - & Mandates screening & Jun 2013 & Sep 2013 & Sep 6, 2013 \\
\hline & $181 \mathrm{Neb}$. Admin. Code 10 & - & $x$ & Screening requirements & Aug 2014 & Aug 2014 & \\
\hline Nevada & Nev. Rev. Stat. § 442.680 & $x^{\Uparrow}$ & - & Mandates screening & Jun 2013 & Jul 2015 & Jul 2015 \\
\hline
\end{tabular}

See table footnotes on the next page. 
TABLE 1. (Continued) State legislation and regulations for newborn screening for critical congenital heart disease (CCHD) — United States, 2011-2018

\begin{tabular}{|c|c|c|c|c|c|c|c|}
\hline State & Citation & Statute* & $\begin{array}{l}\text { Regulation/ } \\
\text { Guidance }^{\dagger}\end{array}$ & Actions & Date enacted & Date effective & $\begin{array}{l}\text { Date universal } \\
\text { screening policy } \\
\text { implemented }^{\S}\end{array}$ \\
\hline New Hampshire & N.H. Rev. Stat. Ann. § 132:10-aa & $x^{\pi}$ & - & Mandates screening & Jun 2012 & Aug 2012 & Aug 11, 2012 \\
\hline \multirow[t]{2}{*}{ New Jersey } & N.J. Rev. Stat. § 26:2-111.4 & $X^{9}$ & - & Mandates screening & Jun 2011 & Aug 2011 & Aug 31, 2011 \\
\hline & N.J. Code Admin. § 8:43G-19.15 & - & $x$ & Reporting requirements & Dec 2013 & Jan 2014 & \\
\hline New Mexico & N.M. Stat. § 24-1-6 & $X^{\pi}$ & - & Mandates screening & Mar 2014 & May 2014 & Jul 1, 2014 \\
\hline New York & N.Y. P.B.H. Law § 2500-A & $x^{q}$ & - & Mandates screening & Jul 2013 & Jan 2014 & $\operatorname{Jan} 27,2014$ \\
\hline \multirow[t]{2}{*}{ North Carolina } & N.C. Gen. Stat. § 130A-125 & $x^{9}$ & - & Mandates screening & May 2013 & May 2013 & Jul 25, 2014 \\
\hline & 10 N.C. Admin. Code 43K.0102-0103 & - & $x$ & $\begin{array}{l}\text { Screening and reporting } \\
\text { requirements }\end{array}$ & Jul 2014 & $\begin{array}{l}\text { Jul } 2014 \text { (temporary } \\
\text { effective date) } \\
\text { Apr } 2015 \\
\text { (permanent } \\
\text { effective date) }\end{array}$ & \\
\hline North Dakota & N.D. Cent. Code § 25-17-06 & $x^{9}$ & - & Mandates screening & Apr 2013 & Aug 2013 & Aug 2013 \\
\hline \multirow[t]{2}{*}{ Ohio } & Ohio Rev. Code $\S 3701.5010$ & $x^{q}$ & - & Mandates screening & Jun 2013 & Sep 2013 & Oct 1, 2014 \\
\hline & Ohio Admin. Code 3701:54 & - & $x$ & Reporting requirements & Jun 2014 & Oct 2014 & \\
\hline \multirow[t]{2}{*}{ Oklahoma } & $\begin{array}{l}\text { Okla. Stat. tit. } 63, \S 1-550.5 \\
\text { Okla. Admin. Code } \S 310: 550\end{array}$ & $X^{\pi}$ & - & Mandates screenin & Apr 2013 & Jul 2013 & Jul 1, 2013 \\
\hline & Okla. Admin. Code $\S 310: 550$ & - & $x$ & $\begin{array}{l}\text { Screening and reporting } \\
\text { requirements }\end{array}$ & Jun 2014 & Sep 2014 & \\
\hline \multirow[t]{2}{*}{ Oregon } & Or. Rev. Stat. § 433.318 & $x^{9}$ & - & Mandates screening & Jun 2013 & Jun 2013 & Mar 1, 2014 \\
\hline & Or. Admin. R. 333-520-0060 & - & $x$ & Screening requirements & $\begin{array}{r}\text { Dec 2013/ } \\
\text { Jun } 2014\end{array}$ & $\begin{array}{l}\text { Jan } 2014 \\
\text { (temporary } \\
\text { effective date) } \\
\text { Jun } 2014 \\
\text { (permanent } \\
\text { effective date) }\end{array}$ & \\
\hline \multirow[t]{2}{*}{ Pennsylvania } & 42 Рa. В. 7348 & - & $x$ & $\begin{array}{l}\text { Mandates reporting if screening is } \\
\text { performed }\end{array}$ & Dec 2012 & Mar 2013 & Sep 2014 \\
\hline & Act of Jul. 2, 2014, P.L. 853, No. 94 & $x^{\pi}$ & - & Mandates screening & Jul 2014 & Sep 2014 & \\
\hline Rhode Island & 216 R.I. Code R. § 20-05-01 & - & $x^{9}$ & Mandates screening & Aug 2014 & Jul 2015 & Jul 1, 2015 \\
\hline \multirow[t]{2}{*}{ South Carolina } & S.C. Code Ann. § 44-37-70 & $x^{\uparrow}$ & - & Mandates screening & Jun 2013 & Sep 2013 & Sep 11, 2013 \\
\hline & S.C. Code Regs. 61-123 & - & $x$ & Screening requirements & Jun 2014 & Jun 2014 & \\
\hline South Dakota & S.D. Codified Laws §34-24-32 & $X^{9}$ & - & Mandates screening & Mar 2013 & Jul 2013 & Jul 2013 \\
\hline \multirow[t]{2}{*}{ Tennessee } & Tenn. Code Ann. § 68-5-507 & $x$ & - & $\begin{array}{l}\text { Creates advisory committee to } \\
\text { develop screening program }\end{array}$ & Mar 2012 & Jan 2013 & May 31, 2013 \\
\hline & Tenn. Comp. R. and Regs. 1200-15-01 & - & $x^{\pi}$ & Mandates screening & May 2013 & May 2013 & \\
\hline \multirow[t]{2}{*}{ Texas } & Tex. HSC. Code $\S 33.011$ & $x^{9}$ & - & Mandates screening & Jun 2013 & Sep 2013 & Aug 7, 2014 \\
\hline & Tex. Admin. Code § 37.78-.79 & - & $x$ & $\begin{array}{l}\text { Screening and reporting } \\
\text { requirements }\end{array}$ & Jul 2014 & Aug 2014 & \\
\hline Utah & Utah Code § 26-10-6 & $x^{9}$ & - & Mandates screening & Mar 2013 & Oct 2014 & Oct 1, 2014 \\
\hline \multirow[t]{2}{*}{ Vermont } & 18 Vt. State. Ann. § 5087 & $x$ & - & Requires screening rules be issued & May 2016 & Jul 2016 & Dec 2016 \\
\hline & 13 Vt. Code R. 140057 & - & $x^{\pi}$ & Mandates screening & Dec 2016 & Dec 2016 & \\
\hline \multirow[t]{2}{*}{ Virginia } & Va. Code Ann. § 32.1-65.1 & $X^{9}$ & - & Mandates screening & $\begin{array}{l}\text { Feb 2014/ } \\
\quad \text { Mar 2014 }\end{array}$ & Jul 2014 & Jan 1, 2015 \\
\hline & $\begin{array}{l}12 \text { Va. Admin. Code } \S 5-71-30 / 12 \text { Va. } \\
\text { Admin. Code } \S 5-71-210\end{array}$ & - & $x^{\uparrow}$ & $\begin{array}{l}\text { Screening and reporting } \\
\text { requirements }\end{array}$ & Aug 2016 & Oct 2016 & \\
\hline Washington & Wash. Rev. Code $\S 70.83 .090$ & $x^{q}$ & - & Mandates screening & Apr 2015 & Jul 2015 & Jul 24, 2015 \\
\hline West Virginia & W. Va. Code § 16-44-2 & $X^{9}$ & - & Mandates screening & Apr 2012 & Jun 2012 & Sep 1, 2012 \\
\hline \multirow[t]{3}{*}{ Wisconsin } & Wis. Stat. § 253.13 & $x$ & - & $\begin{array}{l}\text { Allows the state's department of } \\
\text { health to add conditions to the } \\
\text { state's screening panel of } \\
\text { disorders }\end{array}$ & Mar 2014 & Mar 2014 & Jul 3, 2014 \\
\hline & Wis. Admin. Reg. Em. Rule 1410 & - & $x^{\pi}$ & Mandates screening & Jun 2014 & $\begin{array}{l}\text { Jul } 2014 \\
\quad \text { (emergency } \\
\text { effective date) }\end{array}$ & \\
\hline & Wis. Admin. Code DHS § 115 & - & $x^{9}$ & Mandates screening & Jul 2015 & $\begin{array}{l}\text { Aug } 2015 \\
\text { (permanent } \\
\text { effective date) }\end{array}$ & \\
\hline Wyoming & Wyo. Code R. § 048.0035.1.09072017 & - & $x^{q}$ & Mandates screening & Sep 2017 & Sep 2017 & Sep 7, 2017 \\
\hline
\end{tabular}

Abbreviation: $\mathrm{X}=$ presence of state action.

* Thirty-nine states and District of Columbia (DC) have enacted legislation related to newborn screening for CCHD; laws in 35 of those states (and DC) require screening.

t Thirty-one states issued regulations related to newborn screening; 15 of those states issued regulations requiring screening.

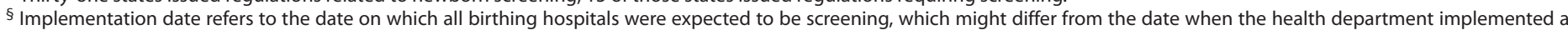

screening policy or reporting requirement.

I Mandates CCHD screening of newborns.

** Direct entry midwives are midwives who typically attend home births and who have become credentialed without first becoming a nurse. 
higher-elevation locations typically have lower normal oxygen saturation levels, which have not yet been incorporated in screening guidelines). One year later, the state required midwives attending home births to either screen newborns or refer the parents to a physician or health facility. Kansas, which previously had a successful voluntary CCHD screening project in place since 2013, added CCHD to its required newborn screening panel by regulation in early 2018. In Idaho, regulations went into effect in July 2018 that require all newborns to be screened for CCHD, including those born outside of a birthing center or hospital.

Forty-one (80\%) jurisdictions reported receiving CCHD screening data from hospitals or birthing centers (Table 2). Among these jurisdictions, $32(78 \%)$ receive some type of individual-level screening results for all infants screened, including 19 jurisdictions that receive all screening data (oxygen saturation values and dates and times of screening), one that receives only data on the final screen, and 12 that receive only the final interpretation result (pass/fail). Five (12\%) of 41 jurisdictions reported receiving only aggregate data on the numbers of infants screened and CCHD cases detected, and four (10\%) reported receiving individual-level screening results (oxygen saturation values and dates and times of screening) only for CCHD cases detected through screening.

Nineteen (37\%) jurisdictions reported data sharing between birth defects surveillance programs and newborn screening programs, maximizing the surveillance capabilities of these public health programs (Table 2). Shared data are used to identify cases of CCHD missed by screening, to ensure cases match between birth defects and newborn screening programs, or to perform postdiagnostic follow-up of infants identified by CCHD screening; six jurisdictions reported sharing for all three purposes. Among the 19 jurisdictions that reported data sharing, five had electronic linkage between newborn screening and birth defects surveillance data systems, two had a shared data system that encompasses both CCHD newborn screening and birth defects, and the remaining 12 shared data manually through direct communication, email, and reports. Among reasons cited by the 32 jurisdictions that do not share data between birth defects surveillance programs and CCHD newborn screening programs are absence of a birth defects surveillance program (five, 16\%); lack of individual-level pulse oximetry screening data $(10,31 \%)$; and data systems that are not linked (17, 53\%).

\section{Discussion}

Policies for newborn screening of CCHD were gradually adopted in all U.S. states and DC from 2011 through 2018, thus facilitating improved survival of affected infants. Newborn screening mandates for CCHD have been found to save lives (3);
TABLE 2. Receipt of critical congenital heart disease (CCHD) screening data and data sharing with birth defects surveillance programs United States, 2018

\begin{tabular}{lc}
\hline Characteristic & $\begin{array}{c}\text { No. (\%) of } \\
\text { jurisdictions }\end{array}$ \\
\hline Receipt of CCHD screening data by jurisdiction & $41(80)^{*}$ \\
Receive any CCHD screening data & $32(7)^{\dagger}$ \\
Receive any individual-level data & $19(46)^{\dagger}$ \\
Receive all individual-level screening data & $4(10)^{\dagger}$ \\
Receive individual screening data for CCHD cases only & $1(2)^{\dagger}$ \\
Receive data on final screen only & $12(29)^{\dagger}$ \\
Receive final pass/fail result & $5(12)^{\dagger}$ \\
Receive aggregate data only & \\
Data sharing with birth defects surveillance systems & $19(37)^{*}$ \\
Data sharing exists & \\
Mechanism of data sharing & $5(26)$ \\
Electronic linkage & $2(11)$ \\
Shared data system & $12(63)$ \\
Manual & $32(63)^{*}$ \\
No data sharing & \\
Reasons for no data sharing & $5(16)$ \\
No birth defects surveillance program & $10(31)$ \\
No individual level pulse oximetry screening data & $17(53)$ \\
Data systems not linked &
\end{tabular}

* Percentage of all 51 jurisdictions (50 U.S. states and the District of Columbia). + Percentage of jurisdictions that receive any data.

$\S$ Percentage of jurisdictions that share data.

" Percentage of jurisdictions that do not share data.

however, opportunities continue for program improvement, particularly around data collection. Despite the implementation of CCHD screening policies in all jurisdictions, data collection efforts have lagged. In 2014, among 43 states that had implemented CCHD screening policies, 24 states were collecting data, although the types of data collected varied by state (4). By 2017, among 49 states with CCHD screening policies implemented, 41 were collecting data. Jurisdictional level data collection practices vary widely based upon state statute, financial and staff member resources, and capabilities to collect data (8). Completeness of data collection is important for surveillance, monitoring of outcomes, process improvement, and evaluation of state CCHD screening programs $(2,4-6,8-10)$. States use screening algorithms as step-by-step guides for screening and determination of pass or fail and for the assessment of false positive and false negative cases $(6,9)$. Evaluation and potential refinement of screening algorithms rely upon individual-level screening and outcome data.

Another opportunity for CCHD screening program evaluation and improvement lies in fostering collaborations between the two public health programs most invested in CCHD screening (newborn screening programs and birth defects surveillance programs). Because of the role of birth defects surveillance programs in monitoring new cases of CCHD, regardless of mode of detection, these programs have the ability to aid in evaluation of CCHD screening by assessing mortality, outcomes, and service utilization by children with 
CCHD (8). Integrating population-level screening and followup data from a CCHD newborn screening program with the targeted oversight of newly identified CCHD cases by birth defects surveillance programs is integral to establishing and maintaining a robust surveillance system. Ultimately, this integration can facilitate evaluation of the complete CCHD screening process, including the effectiveness of and adherence to the screening algorithm, screening sensitivity and specificity, and assessment of outcomes and needs of affected infants and their families. In Minnesota, for example, staff members of the CCHD newborn screening and birth defects surveillance program work together and share data regularly. Birth defects program and follow-up staff members have access to the same data system that collects individual-level CCHD screening data, facilitating rapid reporting of infants identified via CCHD screening to the birth defects surveillance program for diagnostic confirmation and connection to resources. Cases reported to the birth defects surveillance program also can be assessed easily for screening status and results, and previously undetected cases can be documented in the system.

The findings in this report are subject to at least two limitations. First, because of difficulty obtaining exact dates and interpretation of language in jurisdictions' statutes and regulations, slight variability in the legislation, regulations, and guidelines presented might occur. Second, although all 51 jurisdictions completed the survey, the responses were reported by the jurisdictions' CCHD screening contact person and not independently verified.

Newborn screening for CCHD in the United States has been implemented nationwide, with numerous infants' lives being saved or improved as a result. Improved data collection practices and standardization across all jurisdictions could increase effective monitoring and evaluation of CCHD screening. Ongoing evaluation remains important to ensure the best possible outcomes.

Corresponding author: Jill Glidewell, mglidewell@cdc.gov, 404-498-3800.

\footnotetext{
${ }^{1}$ National Center on Birth Defects and Developmental Disabilities, CDC;

${ }^{2}$ American Academy of Pediatrics, Itasca, Illinois; ${ }^{3}$ Minnesota Department of Health; ${ }^{4}$ Association of Public Health Laboratories, Silver Spring, Maryland;

${ }^{5}$ Colorado School of Public Health, University of Colorado, Aurora, Colorado.
}

All authors have completed and submitted the ICMJE form for disclosure of potential conflicts of interest. No potential conflicts of interest were disclosed.

\section{References}

1. US Department of Health and Human Services Office of the Secretary. Letter from the Secretary to the Advisory Committee on Heritable Disorders in Newborns and Children, September 21, 2011. Washington, DC: US Department of Health and Human Services; 2011. https://www. hrsa.gov/sites/default/files/hrsa/advisory-committees/heritable-disorders/ reports-recommendations/response-congenital-cyanotic.pdf

\section{Summary}

What is already known about this topic?

Critical congenital heart disease (CCHD) occurs in two of every 1,000 births and might be undetected at birth. Affected infants are at risk for substantial morbidity and death early in life. In 2011, the U.S. Department of Health and Human Services Secretary endorsed the Advisory Committee on Heritable Disorders in Newborns and Children's recommendation to add $\mathrm{CCHD}$ to the recommended universal newborn screening panel.

What is added by this report?

By 2018, all U.S. states and the District of Columbia had implemented newborn CCHD screening policies. Opportunities for program improvement, particularly around data collection, persist. Not all jurisdictions collect screening data or share data among relevant programs.

What are the implications for public health practice?

All U.S. newborns, regardless of which state they are born in, now have the opportunity to be screened for CCHD.

2. Mahle WT, Newburger JW, Matherne GP, et al.; American Heart Association Congenital Heart Defects Committee of the Council on Cardiovascular Disease in the Young, Council on Cardiovascular Nursing, and Interdisciplinary Council on Quality of Care and Outcomes Research; American Academy of Pediatrics Section on Cardiology and Cardiac Surgery; Committee on Fetus and Newborn. Role of pulse oximetry in examining newborns for congenital heart disease: a scientific statement from the AHA and AAP. Pediatrics 2009;124:823-36. https://doi.org/10.1542/peds.2009-1397

3. Abouk R, Grosse SD, Ailes EC, Oster ME. Association of US state implementation of newborn screening policies for critical congenital heart disease with early infant cardiac deaths. JAMA 2017;318:2111-8. https://doi.org/10.1001/jama.2017.17627

4. Glidewell J, Olney RS, Hinton C, et al. State legislation, regulations, and hospital guidelines for newborn screening for critical congenital heart defects-United States, 2011-2014. MMWR Morb Mortal Wkly Rep 2015;64:625-30.

5. Grosse SD, Riehle-Colarusso T, Gaffney M, et al. CDC grand rounds: newborn screening for hearing loss and critical congenital heart disease. MMWR Morb Mortal Wkly Rep 2017;66:888-90. https://doi. org/10.15585/mmwr.mm6633a4

6. Oster ME, Aucott SW, Glidewell J, et al. Lessons learned from newborn screening for critical congenital heart defects. Pediatrics 2016;137:e20154573. https://doi.org/10.1542/peds.2015-4573

7. Ojodu J, Singh S, Kellar-Guenther Y, et al. NewSTEPs. The establishment of a national newborn screening technical assistance resource center. Int J Neonatal Screen 2018;4:1. https://doi.org/10.3390/ijns4010001

8. CDC. Newborn screening for critical congenital heart disease: potential roles of birth defects surveillance programs-United States, 2010-2011. MMWR Morb Mortal Wkly Rep 2012;61:849-53.

9. Kemper AR, Mahle WT, Martin GR, et al. Strategies for implementing screening for critical congenital heart disease. Pediatrics 2011;128:e1259-67. https://doi.org/10.1542/peds.2011-1317

10. Olney RS, Botto LD. Newborn screening for critical congenital heart disease: essential public health roles for birth defects monitoring programs. Birth Defects Res A Clin Mol Teratol 2012;94:965-9. https:// doi.org/10.1002/bdra.23103 